\title{
Using Ipomoea aquatic as an environmental-friendly alternative to Elodea nuttallii for the aquaculture of Chinese mitten crab
}

\author{
Linlin Shi ${ }^{1,2}$, Meijuan Jin ${ }^{2}$, Shixue Yin ${ }^{\text {Corresp., }}{ }^{3}$, Changying Lu ${ }^{2}$, Haihou Wang ${ }^{2}$, Xingwei Zhou ${ }^{2}$, Lijuan Mei ${ }^{3}$, \\ Mingxing Shen ${ }^{\text {Corresp. } 2}$ \\ ${ }^{1}$ College of Agriculture, Yangzhou University, Yangzhou, Jiangsu, China \\ 2 Research Center of Agricultural Resource and Environment, Institute of Agricultural Science in Taihu Lake District, Suzhou, Jiangsu, China \\ 3 College of Environmental Science and Engineering, Yangzhou University, Yangzhou, Jiangsu, China \\ Corresponding Authors: Shixue Yin, Mingxing Shen \\ Email address: sxyin@yzu.edu.cn, smx@jaas.ac.cn
}

Elodea nuttallii (EN) is widely used in Chinese mitten crab (CMC) rearing practice, but it is not a native aquatic plant and cannot endure high temperature. Thus, large EN mortality and water deterioration events could occur during high temperature seasons. The aim of this study was to identify the use of local macrophytes in CMC rearing practice, including Ipomoea aquatic (IA) and Oryza sativa (OS). A completely randomized field experiment was conducted to investigate the crab yield, water quality, bacterioplankton community and functions in the three different systems (EN, IA, and OS). Average crab yields in the different macrophyte systems did not differ significantly. The IA and OS systems significantly decreased the $\mathrm{TN}$ and $\mathrm{NO}_{3}-\mathrm{N}$ quantities in the outflow waters during the rearing period compared to the EN system, and the IA and OS plants assimilated more nitrogen than the EN plant. Moreover, the significant changes of bacterioplankton abundances and biodiversity in the three systems implied that cleanliness of rearing waters was concomitantly attributed to the differential microbial community and functions. In addition, principle component analysis successfully differentiated the bacterioplankton communities of the three macrophytes systems. Environmental factor fitting and the cooccurrence network analyses indicated that $\mathrm{pH}$ was the driver of bacterioplankton community structure. Functional predictions using PICRUSt (v.1.1.3) software based on evolutionary modeling indicated a higher potential for microbial denitrification in the IA and OS systems. Notably, the OS plants stopped growing in the middle of the rearing period. Thus, the IA system rather than the OS system could be a feasible and environmental-friendly alternative to the EN system in $\mathrm{CMC}$ rearing practice. 
1 Using Ipomoea aquatic as an environmental-friendly alternative to Elodea nuttallii for the 2 aquaculture of Chinese mitten crab

3 Linlin Shi ${ }^{1,2}$, Meijuan Jin², Shixue Yin ${ }^{3, \#, ~ C h a n g y i n g ~ L u ², ~ H a i h o u ~ W a n g ², ~ X i n g w e i ~ Z h o u ², ~}$ 4 Lijuan $\mathrm{Mei}^{3}$, Mingxing Shen ${ }^{2, \#}$

$5 \quad{ }^{1}$ College of Agriculture, Yangzhou University, Jiangsu, China

$6 \quad{ }^{2}$ Research Center of Agricultural Resource and Environment, Institute of Agricultural Science in 7 Taihu Lake District, Jiangsu, China

$8{ }^{3}$ College of Environmental Science and Engineering, Yangzhou University, Jiangsu, China

$9 \quad$ \#Corresponding author: Shixue Yin

10 Email address: sxyin@yzu.edu.cn

$11{ }^{\#}$ Corresponding author: Mingxing Shen

12 Email address: smx@saas.ac.cn

\section{Abstract}

14 Elodea nuttallii (EN) is widely used in Chinese mitten crab (CMC) rearing practice, but it is not

15 a native aquatic plant and cannot endure high temperature. Thus, large EN mortality and water

16 deterioration events could occur during high temperature seasons. The aim of this study was to

17 identify the use of local macrophytes in CMC rearing practice, including Ipomoea aquatic (IA) 
18 and Oryza sativa (OS). A completely randomized field experiment was conducted to investigate

19 the crab yield, water quality, bacterioplankton community and functions in the three different

20 systems (EN, IA, and OS). Average crab yields in the different macrophyte systems did not

21 differ significantly. The IA and $\mathrm{OS}$ systems significantly decreased the $\mathrm{TN}$ and $\mathrm{NO}_{3}{ }^{-}-\mathrm{N}$

22 quantities in the outflow waters during the rearing period compared to the EN system, and the IA

23 and OS plants assimilated more nitrogen than the EN plant. Moreover, the significant changes of

24 bacterioplankton abundances and biodiversity in the three systems implied that cleanliness of

25 rearing waters was concomitantly attributed to the differential microbial community and

26 functions. In addition, principle component analysis successfully differentiated the

27 bacterioplankton communities of the three macrophytes systems. Environmental factor fitting and the co-occurrence network analyses indicated that $\mathrm{pH}$ was the driver of bacterioplankton community structure. Functional predictions using PICRUSt (v.1.1.3) software based on evolutionary modeling indicated a higher potential for microbial denitrification in the IA and OS systems. Notably, the OS plants stopped growing in the middle of the rearing period. Thus, the

IA system rather than the OS system could be a feasible and environmental-friendly alternative to the EN system in $\mathrm{CMC}$ rearing practice.

\section{Introduction}

The Chinese mitten crab (CMC), Eriocheir sinensis, is considered an invasive species in 
mitten crabs were produced (Zeng et al. 2013); crabs were primarily bred in ponds and lakes (Zeng et al. 2013). The mitten crabs produced in Yangcheng Lake, Suzhou, China, are of high quality and have high economic value ( $\mathrm{Gu}$ et al. 2013). Most of the crabs produced in Yangcheng Lake are exported to Shanghai, Hong Kong, and high-profit foreign markets.

Aquatic plants are required for mitten crab farming. The plants provide shelter for the crabs during exuviation, which is an important part of crab growth (Meng et al. 2013). In addition, aquatic plants assimilate excess nutrients, improve water cleanliness, and absorb solar radiation to maintain cool water temperatures. These properties increase crab growth, yield, and quality (Zhan \& Yang 2015).

Elodea nuttallii (EN), a perennial aquatic plant native to North America, provides these benefits, and is thus widely used in CMC aquaculture (Wang et al. 2016). However, EN cannot withstand high temperatures (Zhan \& Yang 2015). In Yangcheng Lake, summer air and water temperatures typically reach $35-40^{\circ} \mathrm{C}$ and $26-34^{\circ} \mathrm{C}$, respectively, which frequently leads to massive EN die off, resulting in serious water quality deterioration (Wu et al. 2016). Under such conditions, crab growth is negatively affected due to loss of shelter for exuviation hiding places and poor water quality (Zhan \& Yang 2015). Consequently, alternative aquatic plants are required to facilitate mitten crab aquaculture in areas such as Yangcheng Lake.

Local plants that have adapted to local conditions are the best candidates for EN replacement. For example, Ipomoea aquatica (IA) is a semiaquatic, tropical/subtropical plant that might be applicable to mitten crab aquaculture (Zhang et al. 2014). IA grows well in shallow waters, 
58 withstands high temperatures, and efficiently removes nutrients (e.g., nitrogen and phosphorous)

59 from water bodies (Liu et al. 2007; Wei et al. 2017). Furthermore, the tender shoots and leaves of

60 IA are consumable, and providing additional economic value. Alternatively, Oryza sativa (OS) is

61 a submerged grain crop that is common in Asia, and its assimilation ability of nitrogen and

62 phosphorus is similar to IA (Nawaz \& Farooq 2017). OS is thus another candidate for EN

63 replacement.

64 Therefore, in this study, we aimed to answer three questions. Which of the two locally adapted

65 plants would most adequately replace EN, similarly improving crab yield and quality? How do

66 the candidate plant systems affect water quality and the associated environmental characteristics?

67 Considering microorganisms play important roles in nutrient conversion in wastewater (Daims et

68 al. 2006), are the two plant systems associated with different bacterioplankton communities that

69 differentially affect water quality? Answers to these questions are of critical importance to crab

70 farmers, and those who are concerned with water quality. Despite the importance of these

71 questions, they remain unanswered. We thus aimed to address the above questions by evaluating

72 candidate aquatic plant systems, and exploring the associated bacterioplankton communities.

73 Material and methods

74 Pond construction, seedling preparation, and floating system construction

75 All of the experiments were performed in Lianzigang, Suzhou, China $\left(31^{\circ} 27^{\prime} 40.18^{\prime \prime}\right.$,

$76120^{\circ} 43.5^{\prime} 5.32^{\prime \prime E}$ ). This region has a subtropical monsoon climate, with an annual average 
77 rainfall of $1076.2 \mathrm{~mm}$ (http://www.pmsc.cn/). Annual average temperature in Lianzigang is 15-

$7817^{\circ} \mathrm{C}$, with high temperatures of $35-40^{\circ} \mathrm{C}$ in July and August (http://www.pmsc.cn/). All of the experiments were conducted between May 1 and November 30, 2017. aeration system, a pond, floating macrophytes, and vertical posts to anchor the macrophytes (Fig. 1). The pond, which was mechanically excavated, had a total area of $1,000 \mathrm{~m}^{2}$ and was $1.5-\mathrm{m}$ deep. The pond was separated into nine sub-ponds with cement walls that were $0.4 \mathrm{~m}$ wide and $1.5 \mathrm{~m}$ high. Each sub-pond had an area of $\sim 100 \mathrm{~m}^{2}$ and an independent staff gauge. Sub-pond bottoms were left in a natural state to allow crabs to burrow, and to facilitate EN root establishment and growth. IA, OS, and EN were grown in separate sub-ponds with three replicates per plant using a completely randomized design. into each sub-pond to a depth of $\sim 10 \mathrm{~cm}$. Basal fertilizer $\left(45 \mathrm{~kg} \mathrm{ha}^{-1}\right.$ of compound-fertilizer; $\left.\mathrm{N}: \mathrm{P}_{2} \mathrm{O}_{5}: \mathrm{K}_{2} \mathrm{O}=15: 15: 15\right)$ was applied 2-3 days before seedling transplantation. containing sufficient nutrients for seedling growth. The matrix had sufficient buoyancy to allow seedlings to float on the surface of the water. Seeds were germinated on the matrix, grown for 30 days in a greenhouse at $25^{\circ} \mathrm{C}$, and then transferred to the bottom of the appropriate sub-ponds. Seedling matrices were arranged side by side until seedling coverage reached $60 \%$ of the total water surface area. Additional water was then pumped into each sub-pond to increase the water 
97 depth to $20 \mathrm{~cm}$, and seedlings were allowed to re-establish growth for 5-7 days. Upon growth re-

98 establishment, water was again gradually and gently pumped into the sub-ponds to increase

99 water depth to $1.0 \mathrm{~m}$. At this depth, all of the seedlings were floating. Seedlings were fixed in

100 place using ropes attached to buoys, which were fastened to posts in the sides of the cement

101 dividers. EN seedlings were directly transplanted from other ponds. EN cluster spacing was 0.5

$102 \mathrm{~m} \times 0.5 \mathrm{~m}$, with forty seedlings per cluster. The transplanted EN plants covered $\sim 60 \%$ of the

103 total water surface area. Upon growth re-establishment, water was pumped into the EN sub-

104 ponds to a depth of $1.0 \mathrm{~m}$.

\section{Crab pond management, nutrient measurements, and crab yield determination}

106 Crab ponds were managed using standard Chinese mitten crab rearing methods (Zhan \& Yang 107 2015). Juvenile crabs, with an average weight of $15 \mathrm{~g}$, were purchased from a local company

108 (Su'an Fishery Co., Ltd., Nantong, China) and added to the experimental sub-ponds at a density of about 12,000 individuals per hectare. Crab feed (bait) was purchased from the Tongwei Group (http://www.tongwei.com/). The nutrient composition of the feed was varied to meet the different needs at each of the growth stages. Crabs were fed twice per day dependent on growth stage, as recommended by the bait manufacturer. Crabs were not dosed with antibiotics or chemical fishery drugs. A micro-porous aeration system was used nightly to ensure sufficient aeration. Approximately $5 \mathrm{~cm}$ of water was pumped out of all ponds each week, and replaced with an equal volume of fresh water from Yangcheng Lake (depending on local precipitation). 
117 immediately frozen at $-20^{\circ} \mathrm{C}$. At the end of the experiment, nutrients in the outflow samples were

118 measured using an auto analyzer (SKALAR SAN ${ }^{++}$, Breda, the Netherlands); the nutrients

119 measured included total nitrogen (TN), total phosphorous (TP), ammonium-N $\left(\mathrm{NH}_{4}{ }^{+}-\mathrm{N}\right)$, nitrate-

$120 \mathrm{~N}\left(\mathrm{NO}_{3}^{-}-\mathrm{N}\right)$, and nitrite-N $\left(\mathrm{NO}_{2}^{-}-\mathrm{N}\right)$. Absolute cumulative nutrient quantity in discharged water

121 was measured by nutrient concentration in discharged water and outflow water quantity

122 estimated by staff gauge. Outflow $\mathrm{pH}$ was measured using a WTW portable $\mathrm{pH}$ meter (ProfLine

123 3310, Weilheim, Germany). Inlet water samples were taken and measured every month during

124 the rearing period, and average nutrient concentrations were finally calculated. Dissolved oxygen

125 (DO) concentrations were not measured, because preliminary studies identified large spatial and

126 temporal variations in DO concentrations (Fig. S1) due to uncontrollable factors (i.e., air

127 temperature, air pressure, water disturbances, aeration, activities of aquatic organisms, and

128 photosynthesis of plants and algae) (Dai et al. 2013).

The biomass yields (TBM) of EN, IA, and OS were estimated by dry matter productivity in unit area (DM) and aquatic plant areas (APA) in each pond. The fresh plant tissues in $1 \mathrm{~m}^{2}$ area were collected and oven-dried with 3 replicates in each pond at the end of the experiment, and average dry weight in $1 \mathrm{~m}^{2}$ area was considered as DM. APA was equal to the $60 \%$ of total area of each pond. Thus, the TBM could be calculated by the equation: $\mathrm{TBM}=\mathrm{DM} \times \mathrm{APA}$. Trimmed plant tissues were included in the biomass production estimates. As IA and EN has a sprawling growth pattern, it was periodically cut back outside of the rope-restricted area to maintain $\sim 60 \%$ coverage to keep constant aquatic plant coverage (Trimming details see Fig. S1-S2). Nutrients 
137 assimilated by the plants were calculated based on plant biomass and nutrient concentrations.

138 The tissue-mixed plant samples that were collected in different growth stages were used for

139 nutrient concentration measurement. Table S1 showed the average nutrient concentrations of

140 plants.

141 To assess crab production, mature crabs were harvested using crab traps, and remaining crabs

142 were captured by hand at night, after the pond water was completely drained. Males and females

143 were manually separated and weighed.

\section{Characterization of bacterioplankton communities}

145 As crab rearing is sensitive to high air temperatures (Yuan et al. 2017), the bacterioplankton 146 communities during periods of high temperatures were more interesting. Thus, the

147 bacterioplankton community was assessed on July 2, 2017, when the maximum air temperature

148 reached $37^{\circ} \mathrm{C}$. To obtain sufficient bacterioplankton biomass for community profiling via DNA

149 sequencing, we collected $10 \mathrm{~L}$ of water at $20 \mathrm{~cm}$ depth from each replicate pond. Water samples

150 were filtered through a $0.22-\mu \mathrm{m}$ polycarbonate membrane (Millipore, Billerica, MA, USA).

151 DNA was extracted from the filtered biomass using a FastDNA Spin Kit for soil (MP bio, Solon,

$152 \mathrm{OH}$, USA), following the manufacturer's protocols. Extracted DNA concentration was

153 determined with a NanoDrop 2000 UV-vis spectrophotometer (Thermo Scientific, Wilmington,

154 NC, USA); DNA quality was assessed with gel electrophoresis on a 1\% agarose gel. The V4

155 hypervariable region of the bacterial 16S rRNA gene was amplified using PCR, with the primers

156 563F (5'-AYTGGGYDTAAAGVG-3') and 802R (5'-TACNVGGGTATCTAATCC-3') 
157 (Cardenas et al. 2010), following previously described protocols (Wang et al. 2017). The 158 amplified PCR products were purified using an AxyPrep DNA Gel Extraction Kit (Axygen 159 Biosciences, Union City, CA, USA), and quantified using a QuantiFluor-ST kit (Promega, 160 Madison, WI, USA), following the manufacturer's instructions. Purified amplicons were pooled 161 in equimolar concentrations and sequenced on an Illumina MiSeq platform (Illumina, San Diego, 162 CA, USA) at Majorbio Bio-Pharm Technology Co. Ltd. (Shanghai, China), following standard 163 protocols.

Raw sequence reads were demutiplexed using QIIME (v.1.9.1) (Caporaso et al. 2010a). Barcoding adapters and PCR primers were cleaved using cutadapt (v.1.16) (Martin 2011). Lowquality reads were removed from the dataset with USEARCH10 (Edgar \& Flyvbjerg 2015), using the "fastq_filter" command with the parameters maxee $=1$ and truncqual $=15$. The remaining paired-end reads were merged using the "fastq_mergepairs" command in USEARCH10 (Edgar \& Flyvbjerg 2015). Merged read abundances were normalized across samples by randomly subsampling 28,000 sequences from each sample. A zero-radius OTU (zOTU) table was produced from the sequence reads using the Unoise3 algorithm (Edgar 2018).

172 The taxonomic classification of each zOTU was assigned using the UCLUST algorithm against 173 the Silva (SSU123) 16S rRNA database with default parameters (Caporaso et al. 2010b; Edgar 174 2010).

175 An additional OTU table was generated to predict bacterioplankton functions. The abundance176 normalized sequences were clustered at the $97 \%$ nucleotide similarity cutoff level into OTUs 
177 using the "pick_closed_reference_otus.py" function in QIIME (v.1.9.1) (Caporaso et al. 2010b).

178 OTUs were taxonomically classified using the UCLUST algorithm (Edgar 2010) against the

179 Greengenes (gg_13_5) reference database (DeSantis et al. 2006) with default parameters. The

180 resulting OTU table was analyzed using PICRUSt (v.1.1.3) (scripts "normalize_by_funtion.py",

181 “predict_metagenomes.py”, “categorize_by_function.py”, and "metagenome_contributions.py")

182 (Langille et al. 2013). The PICRUSt algorithm produced a table of functional Kyoto

183 Encyclopedia of Genes and Genomes (KEGG) orthologs (KOs). To obtain OTU-specific counts

184 of genes (da Fonseca et al. 2019; Fan et al. 2018) associated with nitrification and denitrification,

185 the PICRUSt script "metagenome_contributions.py" with -1 option was applied to selected KOs

186 (K00370, K00371, K00374, K02567, K02568, K00368, K15864, K04561, K02305, K00376,

187 K10535, K10944, K10945, and K10946) (Script S1).

\section{Statistical analysis}

189 Statistical analyses were primarily performed in R (v.3.3.2) (Team 2013). To identify

significant differences among treatments, the Levene and Kolmogorov-Smirnov tests were used

to check the homogeneity of variances and data normality, respectively. One-way ANOVA was

used to determine the significance among the treatments, and Tukey's HSD test was then applied

for multiple comparisons. If the measurement variable did not meet the normality assumption, a

Kruskal-Wallis test was performed instead of one-way ANOVA. We considered $P<0.05$ to be statistically significant, unless otherwise noted. 
197 The matrix of zOTU abundances was transformed prior to distance-based analyses using the

198 "decostand" function with the Hellinger method (Legendre \& Gallagher 2001). Principal 199 component analyses (PCAs) were performed using the "rda" function in vegan to visualize 200 differences among the bacterioplankton communities from the different macrophyte systems. 201 Environmental variables were then fitted and projected onto an ordination using "envfit" 202 function in vegan based on 1,000 permutations.

203 To investigate the correlation of microbial taxa and environmental variables, we constructed a 204 co-occurrence network using CoNet (Faust \& Raes 2016), based on the zOTU table and the 205 environmental variables. In the co-occurrence analysis, the read count matrix was first filtered, 206 and only those zOTUs with at least seven minimum occurrence values across the nine samples 207 were retained. Pair-wise associations among zOTUs and environmental factors were calculated 208 using the Pearson, Spearman, Kendall, Bray-Curtis, and Kullback-Leibler correlation methods. 209 The initial top and bottom edge numbers were set at 1,000. For each edge and each measure of 210 association, 1,000 permutation scores and 1,000 bootstrap scores were computed. The resultant 211 networks were visualized using Cytoscape (v.3.2.1) (Shannon et al. 2003).

\section{Results}

\section{System performance, crab yield, and water quality}

214 The macrophyte systems floated steadily throughout the whole experiment despite two 215 moderate windstorms. Thus, the floating systems described here were suitable for plant growth 
216 on water surfaces. All of the plants grew well initially (between May and August). However, OS

217 began to go to seed (indicating the start of the reproductive stage) in early August, about 25 days

218 earlier than the normal (September, if OS is grown in a field). After early August, OS plants

219 yellowed and the roots darkened. In contrast, IA and EN grew well until the end of the 220 experiment.

Crab yields among the three macrophyte systems did not differ significantly. The average 222 yields of male and female crabs were $\sim 740 \mathrm{~kg} \mathrm{ha}^{-1}$ and $\sim 267 \mathrm{~kg} \mathrm{ha}^{-1}$, respectively (Fig. 2). 223 Individual weight is one of the most important factors determining the value of commercial crabs. 224 Here, the individual weight distributions did not differ significantly among plant systems $(P>$ 225 0.05). The median weights of male and female crabs were $168 \mathrm{~g}$ and $109 \mathrm{~g}$, respectively (Fig. 2).

226 The nitrogen assimilated by IA was estimated to be $118 \mathrm{~kg} \mathrm{ha}^{-1}$, based on macrophyte biomass 227 weight and nutrient concentrations. This level of assimilation was 3.5 times that of EN, and 1.5 228 times that of OS (Fig. 3). In contrast, the phosphorous assimilated by IA, EN, and OS did not 229 differ significantly.

The average TN, TP, $\mathrm{NH}_{4}{ }^{+}-\mathrm{N}$ and $\mathrm{NO}_{3}{ }^{-}-\mathrm{N}$ concentrations of inlet waters in the rearing period were $1.25 \pm 0.44\left(\right.$ Mean \pm SD) $\mathrm{mg} \mathrm{L}^{-1}, 0.03 \pm 0.02 \mathrm{mg} \mathrm{L}^{-1}, 0.25 \pm 0.43 \mathrm{mg} \mathrm{L}^{-1}$ and $0.57 \pm 0.47$

$232 \mathrm{mg} \mathrm{L} \mathrm{m}^{-1}$, respectively (Fig. 4). The TN content in $31.3 \%$ of the samples from the EN system 233 exceeded the Environmental Quality Standards for Surface Water (GB3838-2002) limit for type 234 III water. In contrast, the TN content in $9.4 \%$ and $15.6 \%$ samples from the OS and IA systems, 235 respectively, exceeded the type III water quality limit (GB3838-2002) (Fig. 4). The number of 
236 samples that exceeded the TP and $\mathrm{NH}_{4}{ }^{+}-\mathrm{N}$ type III water quality limits did not differ

237 substantially among treatments. No samples exceeded the water quality limit for $\mathrm{NO}_{3}^{-}-\mathrm{N}(10 \mathrm{mg}$

$238 \mathrm{~L}^{-1}$ ). Cumulative curve analysis indicated that amount of $\mathrm{TP}$ and $\mathrm{NH}_{4}{ }^{+}-\mathrm{N}$ accumulated over the 239 course of the experiment (up to November 27) did not differ significantly among different plant 240 systems. However, the levels of accumulated $\mathrm{TN}$ and $\mathrm{NO}_{3}{ }^{-}-\mathrm{N}$ were significantly higher in the EN 241 system than in the IA or OS systems (Fig. 5). Average $\mathrm{pH}$ was 7.48 in the IA system, 8.16 in the 242 EN system, and 7.9 in the OS system (Fig. 6).

\section{Bacterioplankton}

communities

and

predicted

functions

associated with nitrification/denitrification

The abundances of nearly all of the bacterioplankton phyla differed significantly among macrophyte systems (Fig. 7 A). The abundances of Acidobacteria, Chloroflexi, Firmicutes, $\beta$ compared to the EN system, while the abundances of Actinobacteria, Armatimonadetes, and $\gamma$ Proteobacteria were significantly lower. OTU-based diversity ( $\alpha$-diversity) was higher in the OS and IA systems than in the EN system (Fig. 7 B), suggesting that bacterioplankton communities were more complex in the OS and IA systems than in the EN system.

PCA indicated that the bacterioplankton communities were discrete among the different plants, with the first two axes explaining $83.67 \%$ of the total variation (Fig. 8 A). After fitting environmental variables (Table S2) and bacterioplankton community ordination, we found that pH was significantly associated with community differences (Bonferroni-adjusted $P<0.05$ ) (Fig. 
$2568 \mathrm{~A}$ ). The co-occurrence network analysis also identified $\mathrm{pH}$ as the only environmental factor

257 that co-varied with certain taxa. These pH-correlated taxa included zOTUs belonging to the

258 phyla Acidobacteria, Chloroflexi, Firmicutes, Proteobacteria, and Planctomycetes (Fig. 8 B).

259 The total average abundance of co-occurring zOTUs was 7.7\%, suggesting that $\mathrm{pH}$ influenced

260 the relative abundance of the most abundant members of each community.

261 Potential functions of the bacterioplankton communities were predicted using PICRUSt. We

262 focused specifically on functional genes associated with nitrification and denitrification, as these

263 processes are highly related to nitrogen cycling and are likely to affect nitrogen concentration in

264 pond water. Genes associated with all of the steps of denitrification (napA, napB, nirK, norB,

265 norC, and nosZ; (Kanehisa et al. 2017)) were generally more abundant in the IA and/or OS

266 systems than in the EN system. However, the abundances of narI, narG, and narH, which are

267 only involved in the reduction of nitrate to nitrite (Kanehisa et al. 2017), were lower in the IA

268 and/or OS systems (Fig. 9). The abundances of the nitrifying genes pmoA-amoA, pmoB-amoB,

269 and pmoC-amoC, which are involved in the oxidation of ammonia to hydroxylamine (Kanehisa

270 et al. 2017), were significantly higher in the OS system than in the IA and EN systems. The

271 abundance of hao was not significantly different among the three macrophyte systems, although

272 the abundances of narG and narH were lower in the IA and OS systems than in the EN system

273 (Fig. 9).

274 Discussion

275 The macrophyte system described here floated steadily throughout the whole experiment. In 
276 addition, mitten crab yield and quality did not differ significantly among plant systems (Fig. 2).

277 Thus, our results demonstrated that local plants were a feasible alternative to EN. Indeed, our

278 data indicated that IA was be the best local replacement for EN, as this plant grew well in ponds

279 and provided sufficient shade. In contrast, OS is not a suitable alternative to EN, as it stopped

280 growing in the middle of the experimental period. The mechanisms underlying the different

281 performances of OS and IA were related to the different growth behaviors and nutrient

282 requirements of the two species. OS has several distinctive growth stages, including tillering,

283 heading, ripening and et al. (Zhang et al. 2018), which typically require different levels of

284 nutrients (Fairhurst et al. 2007). For example, during the tillering stage, OS biomass increases

285 much faster than during other stages of OS growth, and consequently requires a more intensive

286 nutrient supply (Nawaz \& Farooq 2017). If the nutrient supply needs are not met (i.e., due to low

287 nutrient concentrations in the water), many tillers become non-productive, and the few remaining

288 productive tillers enter the reproductive stage earlier than normal (Nawaz \& Farooq 2017). In

289 submerged paddy fields, the intensity of nutrient supply is manipulated by top-dressing fertilizers

290 (Fairhurst et al. 2007). However, this technique cannot be used in crab-rearing ponds because it

291 would pollute the water.

292 Unlike OS, IA does not exhibit obvious physiological differences among growth stages. IA

293 has sprawling growth, with biomass increasing over rearing time (from May to November)

294 (Shaltout et al. 2010). Thus, low concentrations of nutrients in the water are sufficient. We

295 consequently concluded that IA is an attractive macrophytic alternative to EN in crab-rearing 
296

297

298

299

300

301

302

303

304

305

306

307

308

309

310

311

312

313

314

315

ponds.

Based on the Chinese national water quality standards (GB3838-2002) (SEPA), 31.3\% of the outflow samples from the EN system contained TN levels in excess of limits for type III waters (Fig. 4). Thus, the outflow from ponds using the EN system is likely to pollute the downstream environment. Fewer outflow samples from the IA and OS systems, as compared to the EN system, had TN levels above the type III water quality limits. These data suggest IA or OS systems would generate less environmental pollution than EN systems. This suggestion was reinforced by the absolute cumulative nutrient quantities in outflow samples (Fig. 5), which showed that the $\mathrm{TN}$ and $\mathrm{NO}_{3}{ }^{-}-\mathrm{N}$ concentrations were significantly higher in the EN system, as compared to the IA and OS systems. Indeed, IA and OS assimilated more nitrogen from the water than did EN (Fig. 3). Thus, it was possible that IA and OS more effectively improved water quality than EN, which is a desirable property for macrophytes grown in crab-rearing ponds. An alternative explanation was that the differences in water quality among plant systems were a result of the activities of macrophyte-specific bacterioplankton communities.

Bacterioplankton communities differed significantly among the three macrophyte systems (Fig.

6), possibly because of the different root deposits produced by the three plants. Terrestrial and macrophytic plants release unique root exudates that drastically alter bacterioplankton community structure (Baudoin et al. 2003; Casamatta \& Wickstrom 2000; Nelson et al. 2013; Tanaka et al. 2012; Zhao et al. 2013). Bacterioplankton community composition might also be regulated by $\mathrm{pH}$, as $\mathrm{pH}$ was the only environmental factor that was significantly associated with 
316 the relative abundances of specific bacterioplankton taxa (Fig. 8). These results were consistent

317 with previous reports, which indicated that $\mathrm{pH}$ affects the community structures of both

318 terrestrial bacteria (Fierer \& Jackson 2006; Lauber et al. 2009; Rousk et al. 2010) and

319 bacterioplankton (Ren et al. 2015). Moreover, the significant increases in bacterioplankton

320 diversity with lower water nutrients in the IA and OS treatments (Figs. 5, 7 B) indicated that

321 biodiversity helped improve water quality, as observed in other aquatic systems (Cardinale 2011;

322 Gregoracci et al. 2012).

323 The predicted functions of the bacterioplankton community also differed among the 324 macrophyte systems, particularly those related to nitrification and denitrification. Most 325 denitrifying genes, especially those associated with the reduction of nitrite, nitric oxide, and 326 nitrous oxide, were more abundant in the IA and OS bacterioplankton communities, as compared 327 to the EN bacterioplankton community (Fig. 9). Moreover, abiotic environmental factors usually 328 control the denitrification process, i.e., $\mathrm{pH}$, temperature and organic carbons (OC). The IA and 329 OS systems that could provide labile OC derived from root exudates (Wang et al. 2018; Xu et al. 330 2008; Zhu \& Cheng 2011) favored denitrification. Overall, the biotic and abiotic influences on 331 denitrification in the IA and OS systems were thought to be co-occurring, consistent with the 332 conclusion in riparian wetlands (Xiong et al. 2017). In addition, concentrations of $\mathrm{NO}_{3}{ }^{-}-\mathrm{N}$ (and $333 \mathrm{TN})$ were lower in the IA and OS systems than in the EN system. Thus, the IA and OS systems 334 might have a higher denitrification potential than the EN system. Meanwhile, there were no 335 obvious differences in the abundance patterns of nitrification-associated genes among 
336 macrophyte systems. The genes responsible for the oxidation of ammonium to hydroxylamine

337 (pmoA-amoA, pmoB-amoB, and $p m o C$-amoC) were significantly more abundant in the OS

338 system (but not the IA system) as compared to the EN system, but the abundances of these genes

339 were relatively low across all of the plant systems, with only $\sim 2-20$ copies per sample. In

340 addition, the gene abundances in nitrification process usually could not accurately predict

341 nitrification potential, which can be affected by other abiotic factors (Francis et al. 2005; Rocca

342 et al. 2015; Yao et al. 2018). Thus, nitrification potential may not vary significantly among these

343 three macrophytes, and further studies are required to validate these coupled nitrification-

344 denitrification processes in future.

345 Conclusions

346 EN is routinely cultivated in ponds used for mitten crab aquaculture. However, EN

347 temperature sensitivity often leads to plant deterioration and decreased water quality at high

348 ambient temperatures, negatively affecting crab production. Here, we successfully designed a

349 floating system to support the growth of IA and OS on the surfaces of crab-rearing ponds. We

350 then compared the crab yield, outflow water quality, and bacterioplankton communities among

351 ponds with EN, IA, and OS macrophyte systems. Our results indicated that IA growth behavior

352 was preferable to that of OS. Crab yields did not differ significantly among systems. Moreover,

353 outflow water quality, as indicated by $\mathrm{TN}$ and $\mathrm{NO}_{3}^{-}-\mathrm{N}$ concentrations, was better in the IA and

354 OS systems than in the EN system, due to the greater nitrogen assimilation of IA and OS as

355 compared to EN. In addition, the microbial communities associated with IA and OS had a greater 
356 denitrification potential than the microbial community associated with EN. Thus, our results

357 indicated mitten crabs could be successfully reared using native aquatic plant. Specifically, IA

358 was a suitable and environmental-friendly replacement for EN, but OS was not.

\section{Data Availability}

361 (SRA) under accession number SRP136316.

\section{Acknowledgments}

Authors would like to thank the anonymous reviewers and Kiran Liversage for their good (www.letpub.com) for its linguistic assistance during the preparation of this manuscript.

\section{References}

Fisheries and aquaculture software. FishStatJ - software for fishery statistical time series.In: FAO Fisheries and Aquaculture Department. Available at http://www.fao.org/fishery/.

Baudoin E, Benizri E, and Guckert A. 2003. Impact of artificial root exudates on the bacterial community structure 
374

375

376

377

378

379

380

381

382

383

384

385

386

387

388

389

390

391

Zoology 60:410-416. 10.1093/czoolo/60.3.410

Caporaso JG, Bittinger K, Bushman FD, DeSantis TZ, Andersen GL, and Knight R. 2010a. PyNAST: a flexible tool for aligning sequences to a template alignment. Bioinformatics 26:266-267. 10.1093/bioinformatics/btp636

Caporaso JG, Kuczynski J, Stombaugh J, Bittinger K, Bushman FD, Costello EK, Fierer N, Pena AG, Goodrich JK, Gordon JI, Huttley GA, Kelley ST, Knights D, Koenig JE, Ley RE, Lozupone CA, McDonald D, Muegge BD, Pirrung M, Reeder J, Sevinsky JR, Tumbaugh PJ, Walters WA, Widmann J, Yatsunenko T, Zaneveld J, and Knight R. 2010b. QIIME allows analysis of high-throughput community sequencing data. Nature Methods 7:335336. $10.1038 /$ nmeth.f.303

Cardenas E, Wu WM, Leigh MB, Carley J, Carroll S, Gentry T, Luo J, Watson D, Gu B, Ginder-Vogel M, Kitanidis PK, Jardine PM, Zhou J, Criddle CS, Marsh TL, and Tiedje JM. 2010. Significant association between sulfatereducing bacteria and uranium-reducing microbial communities as revealed by a combined massively parallel sequencing-indicator species approach. Appl Environ Microbiol 76:6778-6786. 10.1128/AEM.01097-10

Cardinale BJ. 2011. Biodiversity improves water quality through niche partitioning. Nature 472:86-89. 10.1038/nature09904

Casamatta DA, and Wickstrom CE. 2000. Sensitivity of two disjunct bacterioplankton communities to exudates from the cyanobacterium Microcystis aeruginosa Kützing. Microbial Ecology 40:64-73. 10.1007/s002480000035

Chen DW, and Zhang M. 2007. Non-volatile taste active compounds in the meat of Chinese mitten crab (Eriocheir sinensis). Food Chemistry 104:1200-1205. https://doi.org/10.1016/j.foodchem.2007.01.042

Peer] reviewing PDF | (2018:11:32502:2:0:NEW 8 Mar 2019) 
392

393

394 da Fonseca MMB, Minnicelli CF, Silva-Portela RdCB, de Farias MF, dos Santos PRS, Fernandes GJT, and AgnezLima LF. 2019. Unlocking and functional profiling of the bacterial communities in diesel tanks upon additive treatment. Fuel 236:1311-1320. https://doi.org/10.1016/j.fuel.2018.09.107

Dai H, Li Y, Ma X, Wang W, Zhu X, and Li Z. 2013. The research of dissolved oxygen distribution in the crab ecological culture ponds (in Chinese). Journal of Shanghai Ocean University 22:66-73.

Daims H, Taylor MW, and Wagner M. 2006. Wastewater treatment: a model system for microbial ecology. Trends in Biotechnology 24:483-489. https://doi.org/10.1016/j.tibtech.2006.09.002

DeSantis TZ, Hugenholtz P, Larsen N, Rojas M, Brodie EL, Keller K, Huber T, Dalevi D, Hu P, and Andersen GL. 2006. Greengenes, a Chimera-Checked 16S rRNA Gene Database and Workbench Compatible with ARB. Applied and Environmental Microbiology 72:5069.

Dixon P. 2009. VEGAN, a package of R functions for community ecology. Journal of Vegetation Science 14:927930. 10.1111/j.1654-1103.2003.tb02228.x

Edgar RC. 2010. Search and clustering orders of magnitude faster than BLAST. Bioinformatics 26:2460-2461. 10.1093/bioinformatics/btq461

Edgar RC. 2018. Updating the 97\% identity threshold for 16S ribosomal RNA OTUs. Bioinformatics 34:2371-2375. 10.1093/bioinformatics/bty113

Edgar RC, and Flyvbjerg H. 2015. Error filtering, pair assembly and error correction for next-generation sequencing reads. Bioinformatics 31:3476-3482. 10.1093/bioinformatics/btv401

PeerJ reviewing PDF | (2018:11:32502:2:0:NEW 8 Mar 2019) 
410 Fairhurst TH, Witt C, Buresh RJ, and Dobermann A. 2007. Rice: A Pracitical Guide to Nutrient Management (2nd

411 edition). Metro Manila, Philippines: International Rice Research Institute (IRRI). p 136.

412 Fan XY, Gao JF, Pan KL, Li DC, Dai HH, and Li X. 2018. Functional genera, potential pathogens and predicted

413 antibiotic resistance genes in 16 full-scale wastewater treatment plants treating different types of wastewater.

414 Bioresource Technology 268:97-106. https://doi.org/10.1016/j.biortech.2018.07.118

415 Faust K, and Raes J. 2016. CoNet app: inference of biological association networks using Cytoscape.

Fierer N, and Jackson RB. 2006. The diversity and biogeography of soil bacterial communities. Proc Natl Acad Sci

US A 103:626-631. 10.1073/pnas.0507535103

Francis CA, Roberts KJ, Beman JM, Santoro AE, and Oakley BB. 2005. Ubiquity and diversity of ammonia-

Gregoracci GB, Nascimento JR, Cabral AS, Paranhos R, Valentin JL, Thompson CC, and Thompson FL. 2012. Structuring of bacterioplankton diversity in a large tropical bay. PLoS One 7:e31408.

Gu SQ, Wang XC, Tao NP, and Wu N. 2013. Characterization of volatile compounds in different edible parts of 
428 Hanson E, and Sytsma M. 2008. The potential for mitten crab Eriocheir sinensis H. Milne Edwards, 1853

429 (Crustacea: Brachyura) invasion of Pacific Northwest and Alaskan estuaries. Biological Invasions 10:603-614.

430

$10.1007 / \mathrm{s} 10530-007-9156-3$

431

Kanehisa M, Furumichi M, Tanabe M, Sato Y, and Morishima K. 2017. KEGG: new perspectives on genomes, pathways, diseases and drugs. Nucleic Acids Research 45:353-361. 10.1093/nar/gkw1092

433

434

435

436

437

438

Langille MGI, Zaneveld J, Caporaso JG, McDonald D, Knights D, Reyes JA, Clemente JC, Burkepile DE, Thurber RLV, Knight R, Beiko RG, and Huttenhower C. 2013. Predictive functional profiling of microbial communities using 16S rRNA marker gene sequences. Nature Biotechnology 31:814-821. 10.1038/nbt.2676

Lauber CL, Hamady M, Knight R, and Fierer N. 2009. Pyrosequencing-based assessment of soil pH as a predictor of soil bacterial community structure at the continental scale. Appl Environ Microbiol 75:5111-5120. 10.1128/aem.00335-09

Legendre P, and Gallagher ED. 2001. Ecologically meaningful transformations for ordination of species data. Oecologia 129:271-280. 10.1007/s004420100716

Liu J, Dong Y, Xu H, Wang D, and Xu J. 2007. Accumulation of Cd, Pb and Zn by 19 wetland plant species in constructed wetland. Journal of Hazardous Materials 147:947-953. https://doi.org/10.1016/j.jhazmat.2007.01.125

Martin M. 2011. Cutadapt removes adapter sequences from high-throughput sequencing reads. EMBnetjournal: Next Generation Sequencing Data Analysis 17:10-12.

Meng X, Song X, Chen G, Feng Y, Wu L, and Shen Z. 2013. Utilization of natural feed resources in a macrophyte- 
446

447

448

450

451

452

453

454

455

456

457

458

459

460

461

462

dominated lake for aquaculture of Chinese mitten crab (Eriocheir sinensis) and its purification effects on water environment (in Chinese). Journal of Lake Sciences 25:723-728.

Nawaz A, and Farooq M. 2017. Rice Physiology. In: Chauhan BS, Jabran K, and Mahajan G, eds. Rice Production Worldwide. Cham: Springer International Publishing, 455-485.

Nelson CE, Goldberg SJ, Wegley Kelly L, Haas AF, Smith JE, Rohwer F, and Carlson CA. 2013. Coral and macroalgal exudates vary in neutral sugar composition and differentially enrich reef bacterioplankton lineages. ISME J 7:962-979. 10.1038/ismej.2012.161

Ren L, Jeppesen E, He D, Wang J, Liboriussen L, Xing P, and Wu QL. 2015. pH influences the importance of niche-related and neutral processes in lacustrine bacterioplankton assembly. Appl Environ Microbiol 81:31043114. 10.1128/aem.04042-14

Rocca JD, Hall EK, Lennon JT, Evans SE, Waldrop MP, Cotner JB, Nemergut DR, Graham EB, and Wallenstein MD. 2015. Relationships between protein-encoding gene abundance and corresponding process are commonly assumed yet rarely observed. ISME $J$ 9:1693-1699. 10.1038/ismej.2014.252

Rousk J, Baath E, Brookes PC, Lauber CL, Lozupone C, Caporaso JG, Knight R, and Fierer N. 2010. Soil bacterial and fungal communities across a $\mathrm{pH}$ gradient in an arable soil. ISME $J$ 4:1340-1351. 10.1038/ismej.2010.58

SEPA. Environmental Quality Standard for Surface Water (GB3838-2002) (in Chinese). State Environmental Protection Administration of China, Beijing.

463 Shaltout KH, Al-Sodany YM, and Eid EM. 2010. Growth behaviour of the invasive species Ipomoea carnea in the 
464

465

466

467

468

469

470

471

472

473

474

475

476

477

478

479

480

481

Nile Delta, Egypt. Hydrobiologia 656:187-197. 10.1007/s10750-010-0443-0

Shannon P, Markiel A, Ozier O, Baliga NS, Wang JT, Ramage D, Amin N, Schwikowski B, and Ideker T. 2003.

Cytoscape: A software environment for integrated models of biomolecular interaction networks. Genome Research

13:2498-2504. 10.1101/gr.1239303

Tanaka Y, Tamaki H, Matsuzawa H, Nigaya M, Mori K, and Kamagata Y. 2012. Microbial community analysis in the roots of aquatic plants and isolation of novel microbes including an organism of the candidate phylum OP10. Microbes and Environments 27:149-157. 10.1264/jsme2.ME11288

Team RC. 2013. R: A Language and Environment for Statistical Computing. R Foundation for Statistical Computing, Vienna, Austria. Available at https://cran.r-project.org/.

Wang H, Wei Z, Mei L, Gu J, Yin S, Faust K, Raes J, Deng Y, Wang Y, Shen Q, and Yin S. 2017. Combined use of network inference tools identifies ecologically meaningful bacterial associations in a paddy soil. Soil Biology and Biochemistry 105:227-235. https://doi.org/10.1016/j.soilbio.2016.11.029

Wang Q, Liu J, Zhang S, Lian Y, Ding H, Du X, Li Z, and De Silva SS. 2016. Sustainable farming practices of the Chinese mitten crab (Eriocheir sinensis) around Hongze Lake, lower Yangtze River Basin, China. Ambio 45:361373. $10.1007 / \mathrm{s} 13280-015-0722-0$

Wang X, Chen R, Jing Z, Yao T, Feng Y, and Lin X. 2018. Root derived carbon transport extends the rhizosphere of rice compared to wheat. Soil Biology and Biochemistry 122:211-219. https://doi.org/10.1016/j.soilbio.2018.03.024 
482

483

484

486

487

488

489

490

491

492

493

494

495

496

497

nutrient accumulation and translocation in high-yielding japonica/indica hybrids, indica hybrids, and japonica conventional varieties. Field Crops Research 204:101-109. 10.1016/j.fcr.2017.01.001

Wu K, Ma X, Wang Y, Wang W, and Lang Y. 2016. Effect of three water plants decomposition on water quality (in Chinese). Journal of Shanghai Ocean University 25:726-734.

Xiong Z, Guo L, Zhang Q, Liu G, and Liu W. 2017. Edaphic Conditions Regulate Denitrification Directly and Indirectly by Altering Denitrifier Abundance in Wetlands along the Han River, China. Environmental Science \& Technology 51:5483-5491. 10.1021/acs.est.6b06521

Xu X, Kuzyakov Y, Wanek W, and Richter A. 2008. Root-derived respiration and non-structural carbon of rice seedlings. European Journal of Soil Biology 44:22-29. https://doi.org/10.1016/j.ejsobi.2007.09.008

Yao L, Chen C, Liu G, Li F, and Liu W. 2018. Environmental factors, but not abundance and diversity of nitrifying microorganisms, explain sediment nitrification rates in Yangtze lakes. RSC Advances 8:1875-1883. 10.1039/C7RA11956A

Yuan Q, Wang Q, Zhang T, Li Z, and Liu J. 2017. Effects of water temperature on growth, feeding and molting of juvenile Chinese mitten crab Eriocheir sinensis. Aquaculture 468:169-174. https://doi.org/10.1016/j.aquaculture.2016.10.007

Zeng QF, Gu XH, Chen X, and Mao ZG. 2013. The impact of Chinese mitten crab culture on water quality, sediment and the pelagic and macrobenthic community in the reclamation area of Guchenghu Lake. Fisheries Science 79:689-697. 10.1007/s12562-013-0638-1

Peer) reviewing PDF | (2018:11:32502:2:0:NEW 8 Mar 2019) 
500 Zhan J, and Yang X. 2015. Standard aquaculture techniques for Chinese mitten crab (in Chinese). Beijing:

501 Chemical Industry Press.

502 Zhang J, Zhang N, Liu Y-X, Zhang X, Hu B, Qin Y, Xu H, Wang H, Guo X, Qian J, Wang W, Zhang P, Jin T, Chu

503 C, and Bai Y. 2018. Root microbiota shift in rice correlates with resident time in the field and developmental stage.

504 Science China Life Sciences 61:613-621. 10.1007/s11427-018-9284-4

505

506

507

508

509

510

511

512

Zhang Q, Achal V, Xu Y, and Xiang W-N. 2014. Aquaculture wastewater quality improvement by water spinach (Ipomoea aquatica Forsskal) floating bed and ecological benefit assessment in ecological agriculture district. Aquacultural Engineering 60:48-55. https://doi.org/10.1016/j.aquaeng.2014.04.002

Zhao D-Y, Liu P, Fang C, Sun Y-M, Zeng J, Wang J-Q, Ma T, Xiao Y-H, and Wu QL. 2013. Submerged macrophytes modify bacterial community composition in sediments in a large, shallow, freshwater lake. Canadian

Journal of Microbiology 59:237-244. 10.1139/cjm-2012-0554

Zhu J, and Cheng K. 2011. Effect of organic acids exuded from hydroponic plants roots on nitrogen cycling bacteria (in Chinese). Chinese Journal of Environmental Engineering 5:2139-2143. 


\section{Figure 1}

Experimental design and schematics for three macrophyte systems.

Elodea nuttallii (EN), Oryza sativa (OS), and Ipomoea aquatica (IA). Each macrophyte was planted in a separate sub-pond (three replicate ponds per species). The sub-ponds were connected by a series of PVC pipes. Pond water was replenished from the Yangcheng Lake water, and discharged water flowed into a constructed wetland. The growth of all three macrophytes was restricted to $60 \%$ of the pond areas. A micro-porous aeration system was used nightly to ensure sufficient aeration. Photo credit: Linlin Shi.

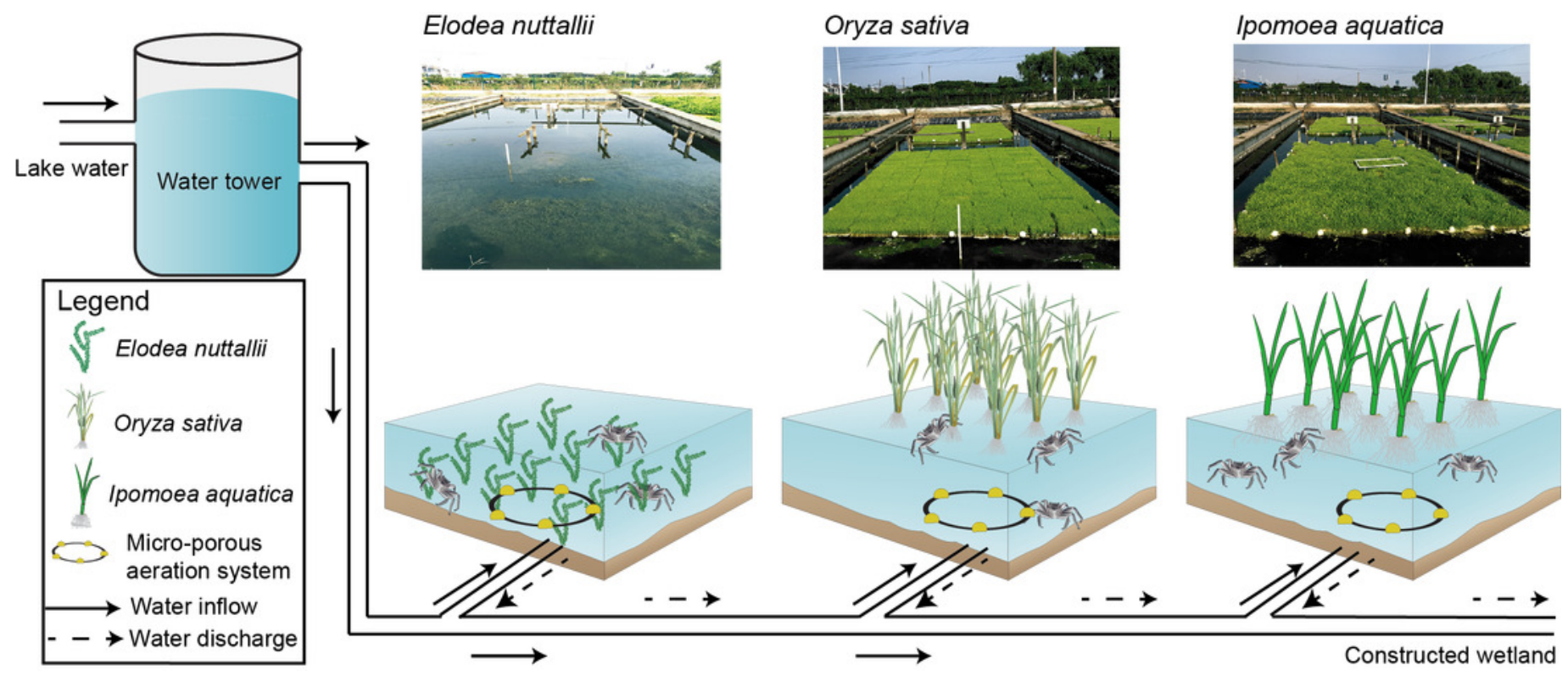




\section{Figure 2 (on next page)}

The yield and individual weight distributions of the Chinese mitten crabs did not differ significantly among macrophyte systems.

Error bars denote the standard deviations of the mean $(n=3)$. EN, Elodea nuttallii; OS, Oryza sativa; IA, Ipomoea aquatica. 

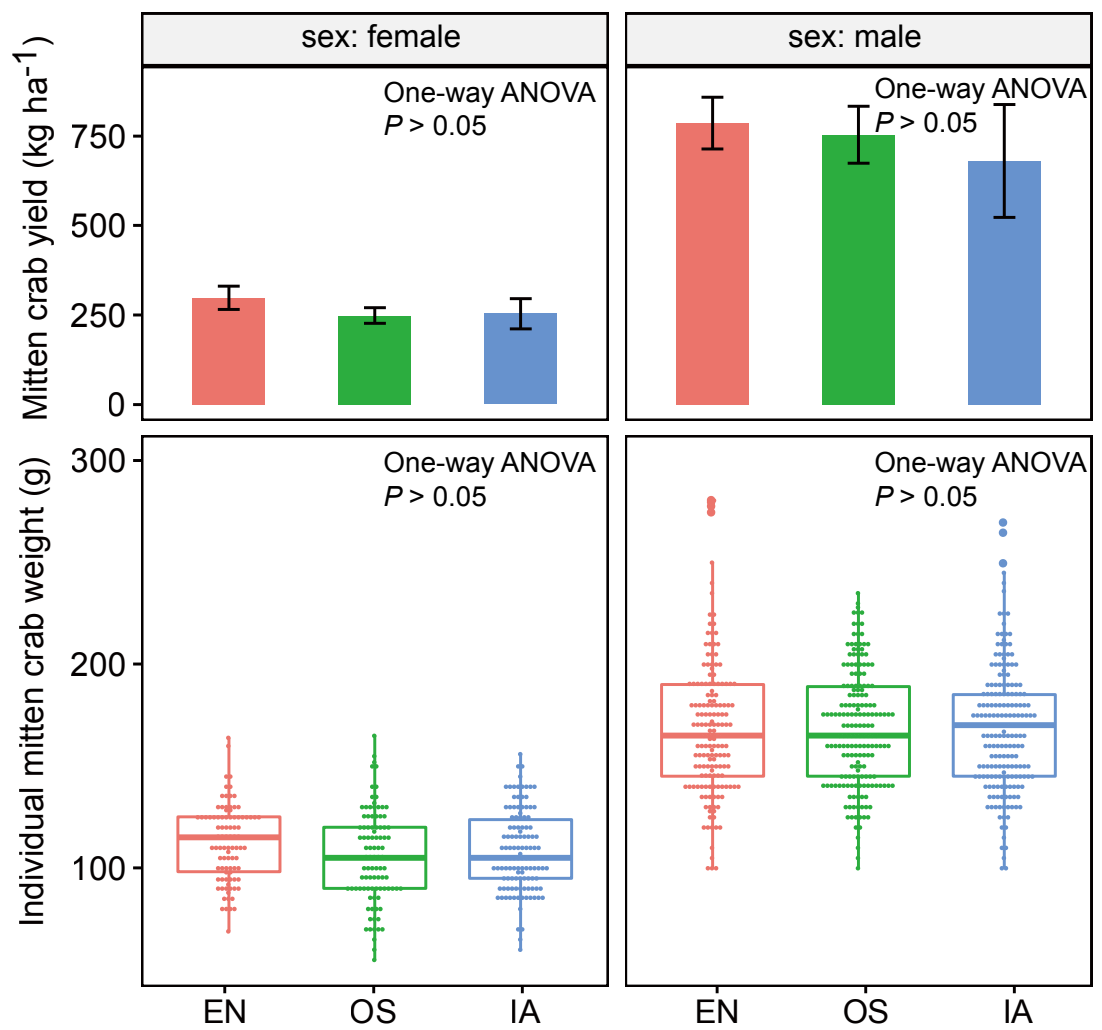
Figure 3 (on next page)

Assimilation of nitrogen and phosphorous by Elodea nuttallii (EN), Ipomoea aquatica (IA), and Oryza sativa (OS).

Different letters above bars represent significant differences among plant systems $(P<0.05$;

Tukey's HSD test). Error bars denote the standard deviations of the means $(n=3)$. 


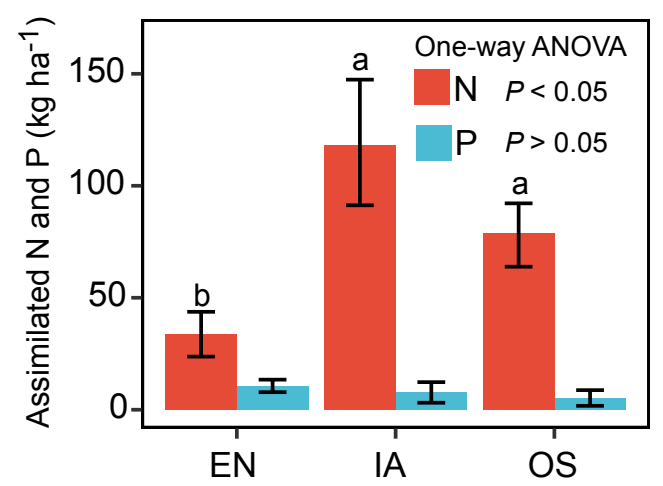


Figure 4 (on next page)

Figure 4 (A-D) separately shows the $\mathrm{TN}, \mathrm{TP}, \mathrm{NH}_{4}{ }^{+}-\mathrm{N}$ and $\mathrm{NO}_{3}{ }^{-} \mathrm{N}$ concentrations in the rearing pond.

Error bars denote the standard deviations of the means $(n=3)$. The brown dashed lines represent the average nutrient concentrations in the inlet waters during the rearing period. The grey dashed lines represent the type III water quality limits from the Chinese Environmental Quality Standard for Surface Water (GB3838-2002). $\mathrm{NO}_{3}^{-}-\mathrm{N}$ concentrations were all below the type III water quality limit $\left(10 \mathrm{mg} \mathrm{L}^{-1}\right)$. EN, Elodea nuttallii; OS, Oryza sativa; IA, Ipomoea aquatica. 


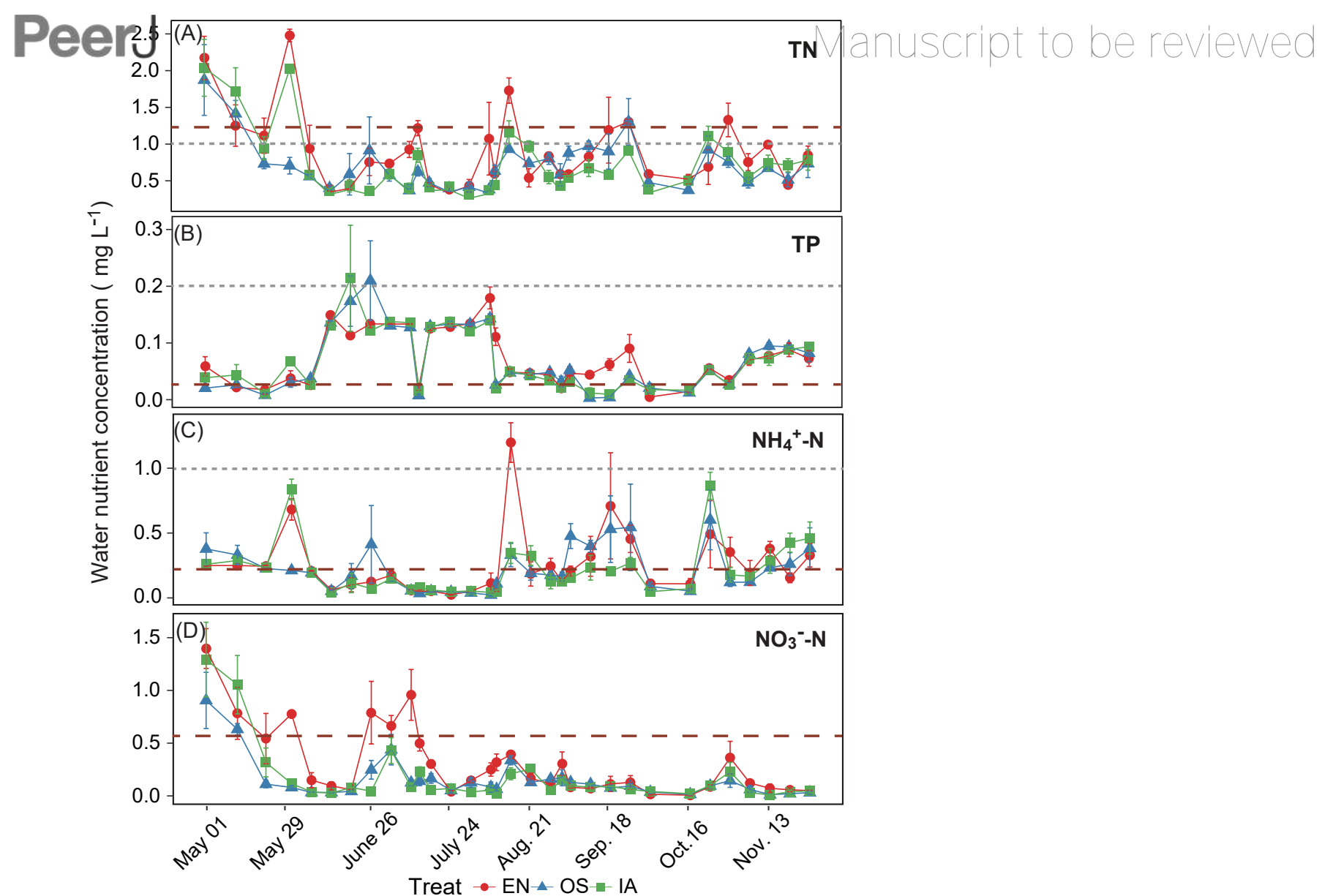


Figure $\mathbf{5}$ (on next page)

Figure $5(A-D)$ separately shows the absolute cumulative $\mathrm{TN}, \mathrm{TP}, \mathrm{NH}_{4}{ }^{+}-\mathrm{N}$ and $\mathrm{NO}_{3}{ }^{-} \mathrm{N}$ quantities in rearing period.

The statistical significance of differences in cumulative nutrient quantity among macrophyte systems was determined with a Kruskal-Wallis test $(n=3)$ at the end of the rearing periods (November 27). Different lowercase letters represent significant differences ( $P<0.05$; Tukey's HSD test). EN, Elodea nuttallii; OS, Oryza sativa; IA, Ipomoea aquatica. 

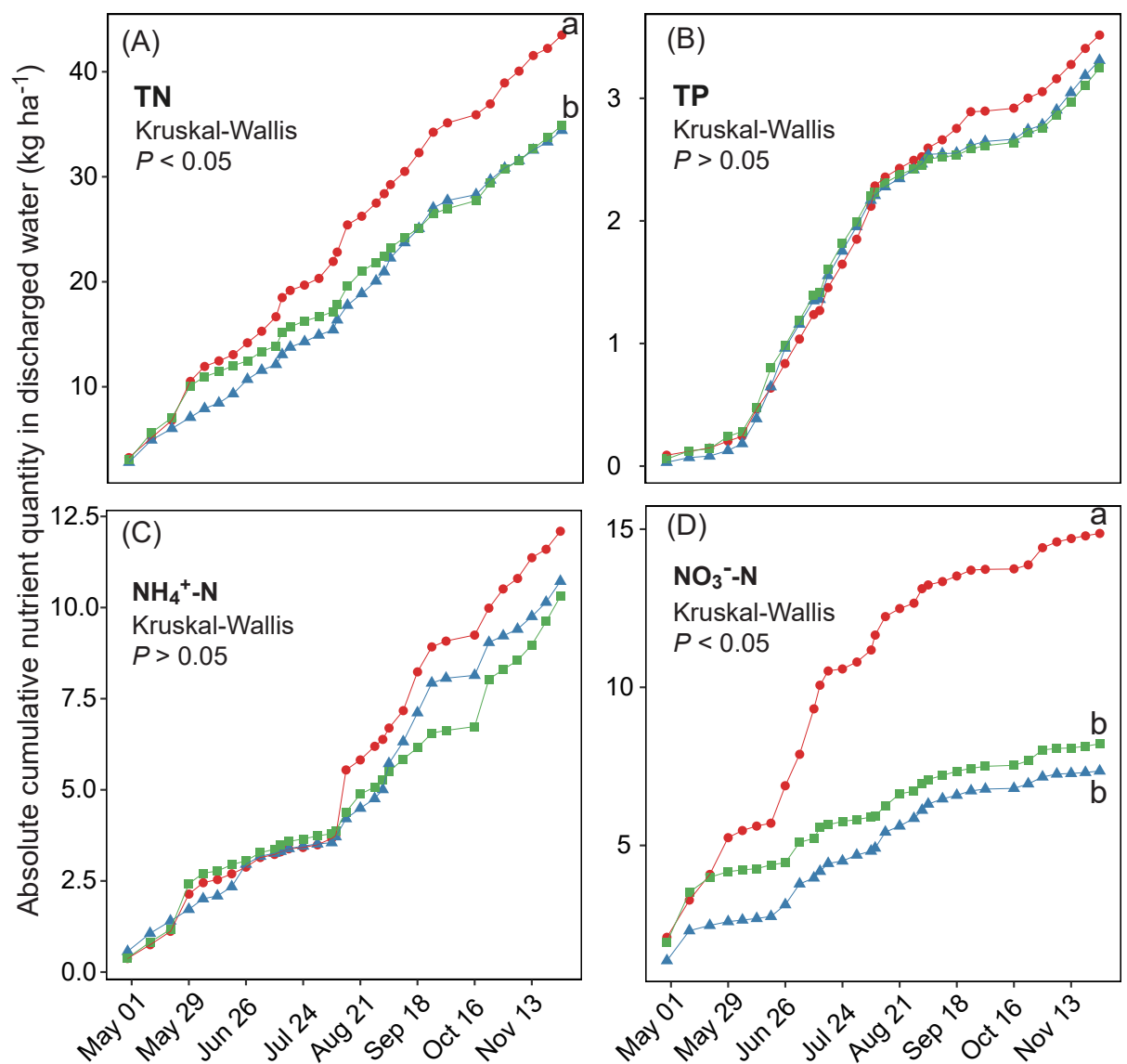

Treat $\bullet \mathrm{EN}-\mathrm{OS}-\mathrm{IA}$ 
Figure 6 (on next page)

$\mathrm{pH}$ of the outflow water samples during the rearing period.

EN, Elodea nuttallii; OS, Oryza sativa; IA, Ipomoea aquatica. 


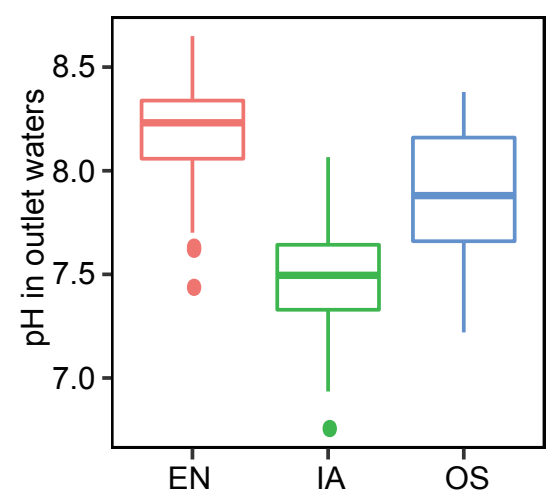


Figure 7 (on next page)

Bacterioplankton abundances and diversity indices of the three macrophytes systems.

(A) The relative abundances of the dominant bacterial phyla in the bacterioplankton communities, and (B) the associated alpha diversity. Asterisks indicate significant differences in abundances among the macrophyte systems ( $P<0.05$ level; one-way ANOVA; $n=3)$. Error bars denote the standard errors of the means. Different letters above bars represent significant differences among treatments $(P<0.05$; Tukey's HSD test; one-way ANOVA; $\mathrm{n}=3$ ). EN, Elodea nuttallii; OS, Oryza sativa; IA, Ipomoea aquatica. 


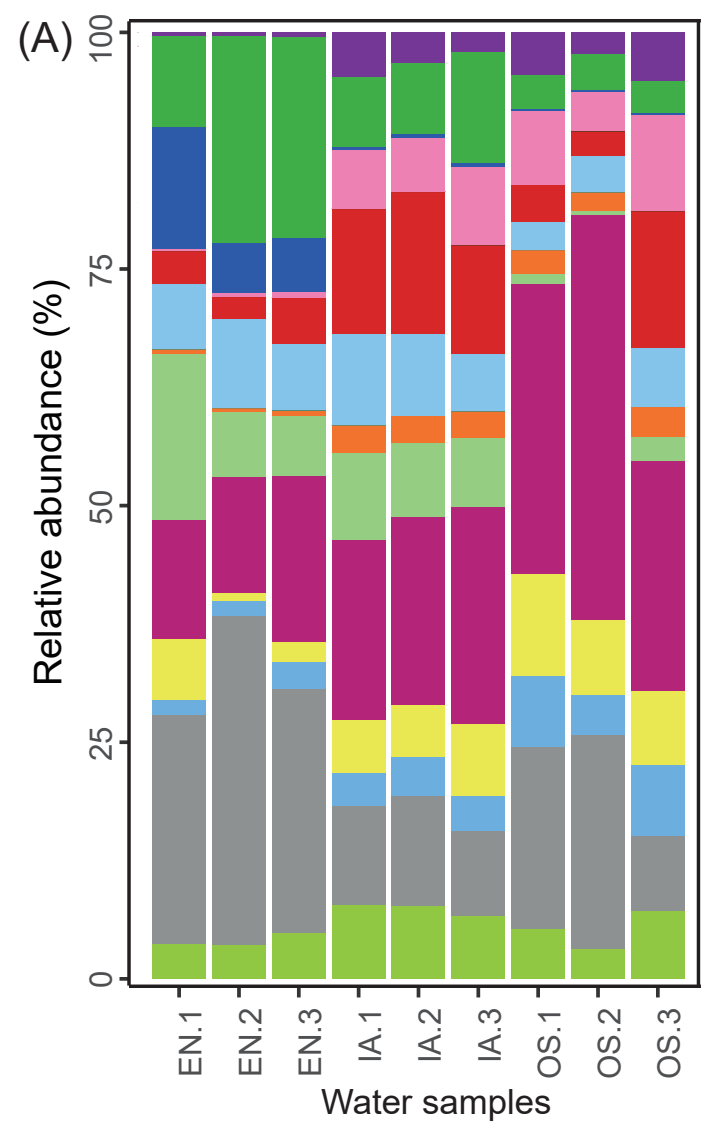

Phylum

Acidobacteria*

Actinobacteria*

Armatimonadetes

Chloroflexi *

Firmicutes*

Planctomycetes*

Unclassified

Verrucomicrobia*

$\alpha$-proteobacteria*

ß-proteobacteria*

$\delta$-proteobacteria* y-proteobacteria*

Others

(B)
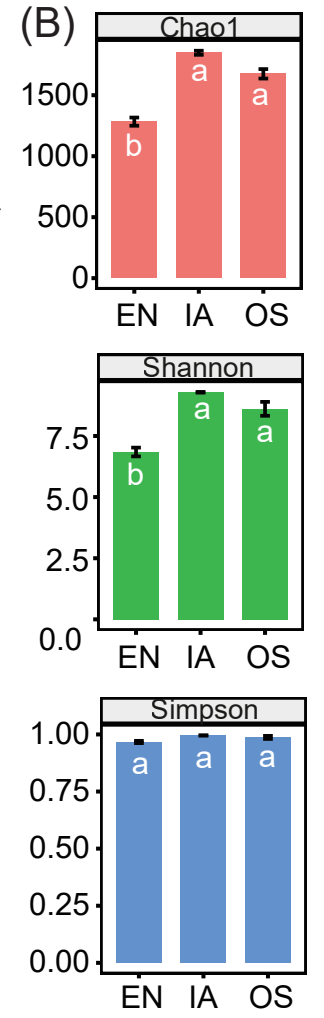

Alpha-diversity 


\section{Figure 8 (on next page)}

Bacterioplankton community structure and environmental factors.

(A) Principal component analysis (PCA) of bacterioplankton community composition and environmental variables. The significant environmental variable $(P<0.05)$ is shown with a black arrow; other factors are shown in gray. EN, Elodea nuttallii; OS, Oryza sativa; IA, Ipomoea aquatica. (B) Subnetwork showing the correlation between bacterial taxa and $\mathrm{pH}$. Squared nodes correspond to environmental parameters and circle nodes correspond to zOTUs. Circle nodes not assignable to genus are labeled with the names of higher taxonomic ranks, and node colors represent phyla. Red and blue colors of edge represent negative and positive correlations, respectively. 


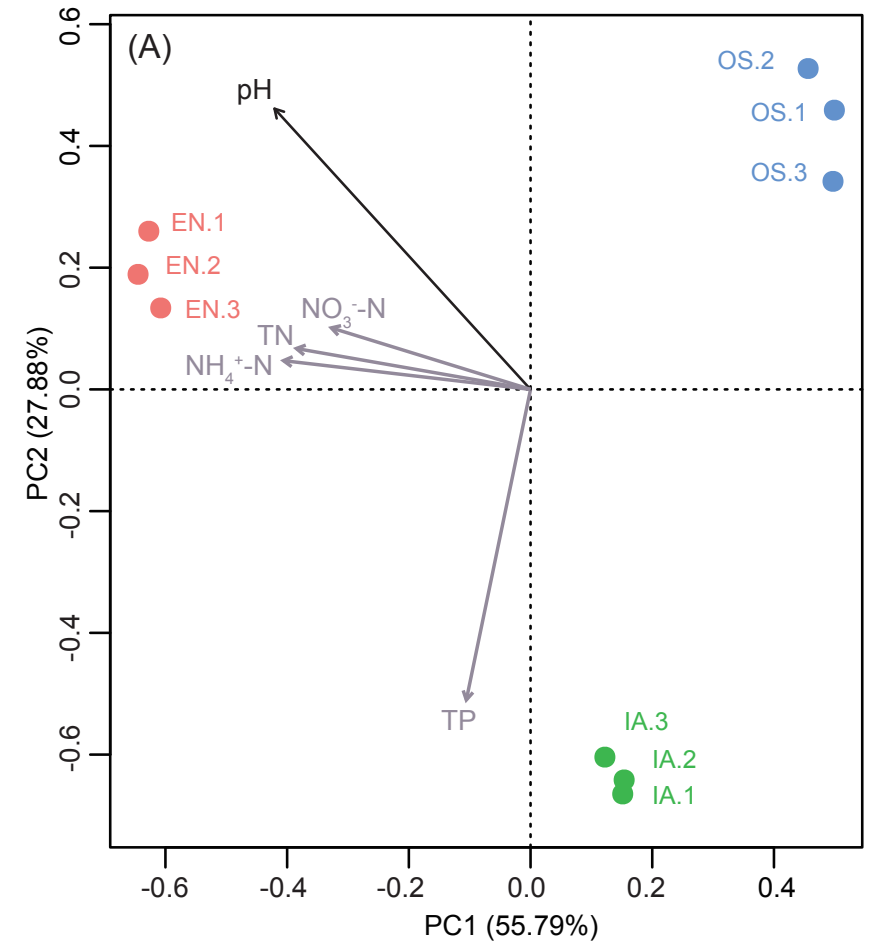

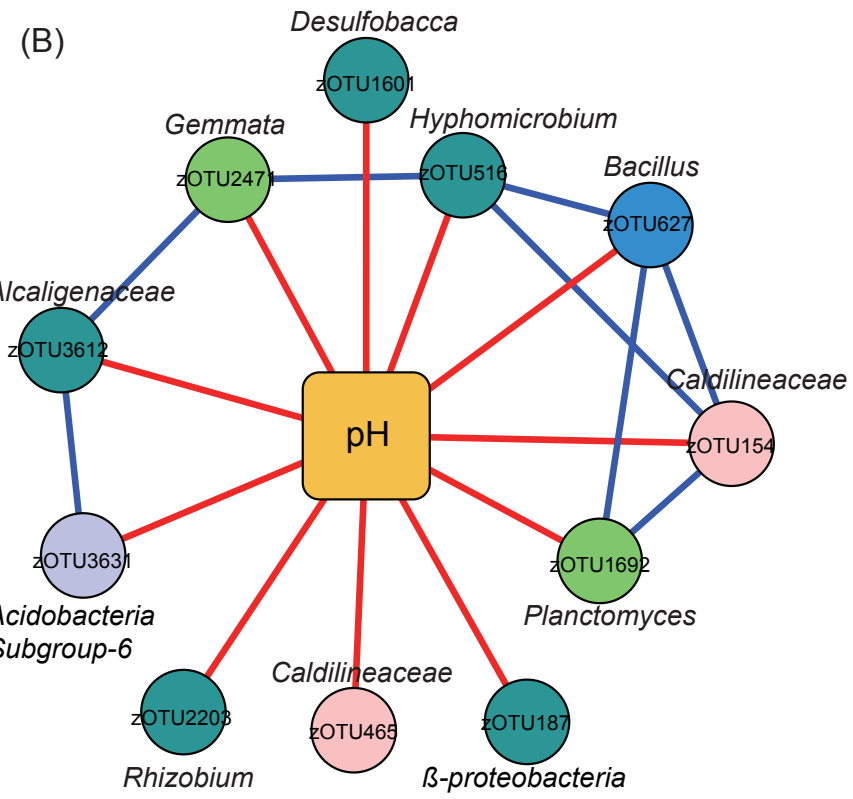

Acidobacteria

Planctomycetes
Chloroflexi

Firmicutes 
Figure 9 (on next page)

The abundances of the bacterioplankton genes associated with nitrification and denitrification among macrophyte systems, as predicted by PICRUSt.

(A) and (B) shows the denitrification and nitrification predicted gene abundances, respectively. Error bars denote the standard deviations of the means $(n=3)$. Different lowercase letters above bars represent statistically significant differences $(P<0.05$; one-way ANOVA followed by Tukey's HSD tests). EN, Elodea nuttallii; OS, Oryza sativa; IA, Ipomoea aquatica. 
(A) Denitrification pathway $\square \mathrm{EN} \square \mathrm{IA} \square$ oS

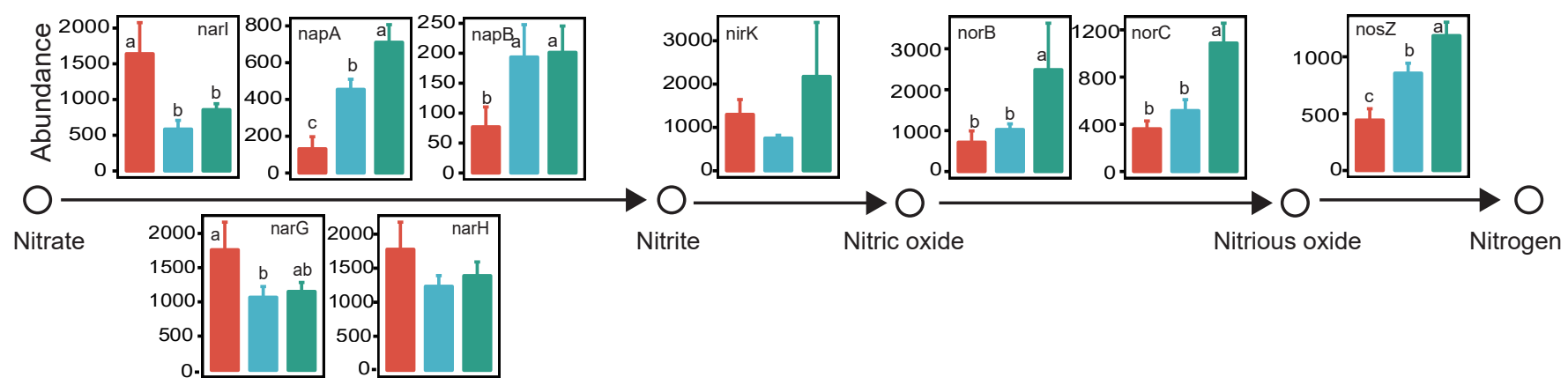

(B) Nitrification pathway $\square \mathrm{EN} \amalg \mathrm{IA} \square \mathrm{OS}$

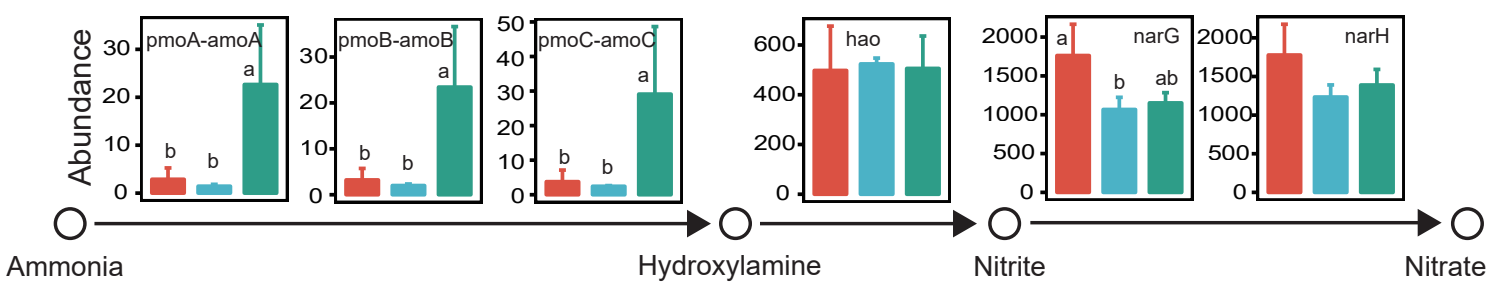

